\title{
Acetylcholinesterase and Butyrylcholinesterase Inhibitory Properties of Functionalized Tetrahydroacridines and Related Analogs
}

Haixiao Jin', Thuy Nguyen ${ }^{2,3}$ and Mei-Lin Go ${ }^{3 *}$

${ }^{1}$ Key Laboratory of Applied Marine Biotechnology, Ministry of Education, School of Marine Sciences, Ningbo University, Ningbo, Fenghua Road 818, Jiangbei District, Zhejiang, 315211, People's Republic of China

${ }^{2}$ Department of Medicinal Chemistry, School of Pharmacy, Virginia Commonwealth University, 800E Leigh Street, Richmond, VA 23298-0540, USA

${ }^{3}$ Department of Pharmacy, National University of Singapore, 18 Science Drive 4, Republic of Singapore 117543

\begin{abstract}
Functionalized acridines, tetrahydroacridines and quinolines were evaluated for in vitro AChE and BChE inhibitory activities. Potent nanomolar inhibition of both enzymes was found in the tacrine-donepezil hybrid $\mathrm{N}$-(1-benzylpiperidin4-yl)-6-chloro-1,2,3,4-tetrahydroacridin-9-amine (51). Molecular modelling and kinetic studies support the notion that 51 occupied the catalytic and peripheral anionic sites of AChE. The physicochemical properties (polar surface area, lipophilicity, hydrogen bonding characteristics) of 51 were within the threshold limits for permeability across the blood brain barrier. Thus, 51 is a promising hybrid inhibitor derived from two established AChE inhibitors with clinical relevance to neurodegenerative diseases.
\end{abstract}

Keywords: Acetyl cholinesterase inhibition; Butyrylcholinesterase inhibition; Neurodegenerative diseases; Physicochemical features for BBB permeability; Tacrine-donepezil hybrid

\section{Introduction}

Tacrine (9-amino-1,2,3,4-tetrahydroacridine) is a reversible inhibitor of acetylcholinesterase (AChE) and butyrylcholinesterase (BChE) and the first drug to be approved by the Food and Drug Administration of United States of America for the palliative treatment of Alzheimer's disease (AD) (Figure 1) [1]. The cholinergic tone of the brain is postulated to be suppressed in $\mathrm{AD}[2,3]$. By increasing the levels of acetylcholine (ACh) in the brain through its cholinesterase inhibitory activity, tacrine is postulated to reverse the cholinergic deficit associated with AD.Unfortunately, the clinical effects of tacrine were found to be short-lived and further compounded by hepatotoxicity which resulted in its withdrawal from clinical use [4]. Nonetheless, there was continued interest in the tacrine moiety, with an emphasis on cholinesterase inhibitory tacrine hybrids that might be safer and more effective alternatives to tacrine. Hybrid molecules with multitargeting potential are deemed to be promising disease modifying agents in view of the multimodal pathogenesis of $\mathrm{AD}$. Thus tacrine hybrids incorporating melatonin [5] orcarbazole [6] were designed to tap on the antioxidant potential of the latter moieties, as free radical formation and oxidative stress have been implicated as early events in $\mathrm{AD}$ [7]. In the same way, functionalities with monoamine oxidase (MAO), N-methyl-D-aspartic acid (NMDA) receptor or cannabinoid receptor (CB-1) inhibitory properties were covalently linked to tacrine in order to intercept signalling along AD-related pathways linked to these neurotransmitters/ligands [8-10].

Another area of interest was to design dual binding inhibitors that occupy both substrate binding sites (catalytic anionic site CAS, peripheral anionic site PAS) of AChE. While hydrolysis of the substrate ACh occurs primarily at the CAS, the PAS which is located at the mouth of the gorge-like binding pocket of the enzyme, serves to increase the concentration of $\mathrm{ACh}$ at that site. In this way, sufficient amounts of Ach are directed to the CAS which lies at the base of the narrow binding pocket [11]. Accordingly, ligands that span both sites are postulated to be more potent inhibitors of AChE. Furthermore, the PAS has an additional non-cholinergic role in $\mathrm{AD}$ in that it is the site at which AChE interacts with $\beta$ amyloid to initiate amyloid fibrillogenesis, a key event in the neurotoxic cascade of $\mathrm{AD}$ [11]. The co-crystallized structure of tacrine with electric eel AChE showed that it binds to the
CAS [12], but a computational study proposed that it binds to the PAS, but with weaker affinity [13]

Tacrine is a small and under functionalized molecule and it is of interest to determine if structural elaboration would result in more potent cholinesterase inhibitors with dual binding features. To that end, we screened a library of 60 functionalized acridine, tetrahydroacridine and quinoline analogs for inhibition of human $\mathrm{AChE}$ and equine BChE. Inhibition was monitored at a fixed concentration of $3 \mu \mathrm{M}$ and compounds that inhibited enzyme activity by $\geq 75 \%$ were shortlisted for IC $_{50}$ (concentration required to reduce basal enzymatic activity by $50 \%)$ determination. We identified one analog [N-(1-benzylpiperidin4-yl)-6-chloro-1,2,3,4-tetrahydroacridin-9-amine, 51] with potent (nanomolar) inhibition of $\mathrm{AChE}$ and BChE (Table 1). Interestingly the 1-benzylpiperidin-4-yl side chain of 51 is also present in donepezil, another FDA approved drug for AD (Figure 1) [14]. Thus 51 is a tacrine-donepezil hybrid and molecular docking in the AChE binding pocket showed that it binds to both the CAS and PAS binding pocket, as reported for donepezil [15]

\section{Group 1}

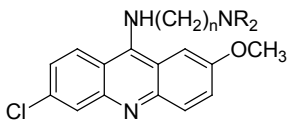

\begin{tabular}{|c|c|c|c|}
\hline Compound & Side chain (R) & \% Inhibition AChEa & \% Inhibition BChE \\
\hline $\mathbf{1}$ & $\mathrm{n}=2, \mathrm{R}=\mathrm{C}_{2} \mathrm{H}_{5}$ & $30.4 \pm 6.0$ & $83.9 \pm 1.5$ \\
\hline $\mathbf{2}$ & $\mathrm{n}=3, \mathrm{R}=\mathrm{CH}_{3}$ & $32.6 \pm 3.4$ & $63.5 \pm 4.6$ \\
\hline $\mathbf{3}$ & $\mathrm{n}=3, \mathrm{R}=\mathrm{C}_{2} \mathrm{H}_{5}$ & $47.4 \pm 3.9$ & $66.3 \pm 0.4$ \\
\hline $\mathbf{4}$ & $\mathrm{n}=4, \mathrm{R}=\mathrm{C}_{2} \mathrm{H}_{5}$ & $65.5 \pm 1.0$ & $79.5 \pm 1.0$ \\
\hline
\end{tabular}

*Corresponding authors: Mei-Lin Go, Department of Pharmacy, Nationa University of Singapore, 18 Science Drive 4, Republic of Singapore 117543; Singapore, Tel:+65 6516 2654; Fax:+65 6779 1554;E-mail: phagoml@nus.edu.sg

Received August 30, 2014; Accepted September 24, 2014; Published September 26, 2014

Citation: Jin H, Nguyen T, Mei-Lin G (2014) Acetylcholinesterase and Butyrylcholinesterase Inhibitory Properties of Functionalized Tetrahydroacridines and Related Analogs. Med chem 4: 688-696. doi:10.4172/2161-0444.1000213

Copyright: @ $2014 \mathrm{Jin} \mathrm{H}$, et al. This is an open-access article distributed under the terms of the Creative Commons Attribution License, which permits unrestricted use, distribution, and reproduction in any medium, provided the original author and source are credited. 
Citation: Jin H, Nguyen T, Mei-Lin G (2014) Acetylcholinesterase and Butyrylcholinesterase Inhibitory Properties of Functionalized Tetrahydroacridines and Related Analogs. Med chem 4: 688-696. doi:10.4172/2161-0444.1000213

Group 2

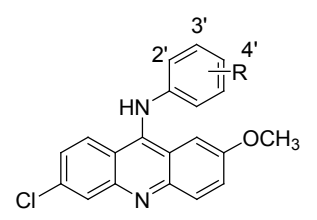

$6 \quad 3^{\prime}-\mathrm{N}\left(\mathrm{CH}_{3}\right)_{2}$

$7 \quad 4^{\prime}-\mathrm{N}\left(\mathrm{CH}_{3}\right)_{2}$

$8 \quad 3-\mathrm{N}\left(\mathrm{C}_{2} \mathrm{H}_{5}\right)_{2}$

$9 \quad 4^{\prime}-\mathrm{N}\left(\mathrm{C}_{2} \mathrm{H}_{5}\right)_{2}$

10

11

12

13

14

15

16

17

18

19

19

20

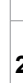

21

22

23

\begin{tabular}{|c|c|c|c|}
\hline 23 & $\prod_{\mathrm{N}} \mathrm{N}-\mathrm{CH}_{3}$ & $28.5 \pm 4.3$ & $35.3 \pm 0.2$ \\
\hline 24 & $\left.4^{\prime}-\mathrm{CH}_{2}-\mathrm{N}^{\prime}\right\rangle$ & $62.1 \pm 0.3$ & $79.6 \pm 0.8$ \\
\hline 25 & $\mathrm{H}$ & $40.9 \pm 5.0$ & $30.5 \pm 4.5$ \\
\hline 26 & $4^{\prime}-\mathrm{CN}$ & $19.2 \pm 2.2$ & $-1.7 \pm 3.4$ \\
\hline 27 & $4^{\prime}-\mathrm{F}$ & $45.8 \pm 6.4$ & $0.7 \pm 0.9$ \\
\hline 28 & 3', 4'-diF & $47.2 \pm 7.6$ & $-4.6 \pm 5.6$ \\
\hline 29 & 4'- $-\mathrm{OCH}_{3}$ & $46.4 \pm 9.8$ & $31.3 \pm 4.4$ \\
\hline 30 & 3'-OH & $5.3 \pm 4.7$ & $-3.6 \pm 1.6$ \\
\hline 31 & 3',4'-diOH & $47.4 \pm 4.0$ & $-1.7 \pm 3.8$ \\
\hline
\end{tabular}

Group 3

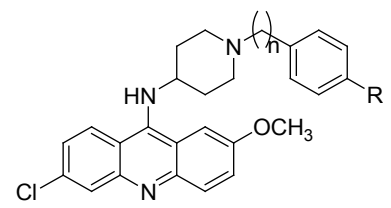
$\%$ Inhibition AChE ${ }^{a}$

$\%$ Inhibition BChE

$48.0 \pm 9.9$

$18.4 \pm 7.6 \quad 86.3 \pm 1.2$

$50.6 \pm 2.8 \quad 57.1 \pm 4.6$

$31.7 \pm 1.8$

$51.6 \pm 5.4$

$55.9 \pm 2.7$

$80.5 \pm 1.6$

$65.6 \pm 7.7$

$38.6 \pm 0.9$

$68.3 \pm 2.7$

$19.6 \pm 4.9$

$50.7 \pm 2.4$

$51.3 \pm 1.7$

$68.3 \pm 2.7$

$\mathrm{ND}^{\mathrm{b}}$

$10.2 \pm 7.9$

$14.7 \pm 0.7$

$6.5 \pm 4.9$

$25.1 \pm 5.6$

$49.6 \pm 1.9$

$4-\mathrm{CH}_{2}-\mathrm{N} \mathrm{N}^{\mathrm{N}-\mathrm{CH}_{3}}$

$43.7 \pm 2.7$

$23.7 \pm 5.7$

$30.4 \pm 3.9$

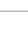




\begin{tabular}{|l|l|l|}
\hline 52 & $82.1 \pm 1.3$ & $34.6 \pm 5.3$ \\
\hline 53 & $81.6 \pm 3.0$ & $50.7 \pm 5.7$ \\
\hline 54
\end{tabular}

Group 7<smiles>[R]c1ccnc2cc(Cl)ccc12</smiles>

\begin{tabular}{|c|c|c|c|}
\hline Compound & Side chain (R) & \% Inhibition AChE & \% Inhibition BChEa \\
\hline $\mathbf{5 5}$ & $\mathbf{5}$ & $0.4 \pm 5.4$ & $2.0 \pm 0.5$ \\
\hline $\mathbf{5 6}$ & & $6.6 \pm 1.4$ & $4.4 \pm 1.3$ \\
\hline $\mathbf{5 7}$ & \\
\hline $\mathbf{5 8}$ & \\
\hline $\mathbf{5 9}$ & \\
\hline $\mathbf{6 0}$ & \\
\hline
\end{tabular}

$\mathrm{a}: \%$ Inhibition is presented as mean \pm SEM from 3 independent determinations. b: Not determined

Table 1: Percent inhibition of AChE and BChE by compounds in Groups 1-7 tested at a fixed concentration of $3 \mu \mathrm{M}$.
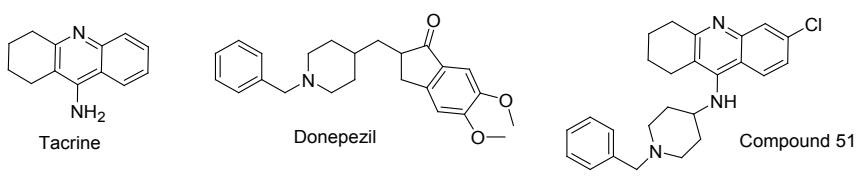

Figure 1: Structures of tacrine, donepezil and tacrine-donepezil hybrid $\mathbf{5 1}$

\section{Materials and Methods}

\section{Characterization of $\mathrm{N}$-(1-benzylpiperidin-4-yl)-6-chloro-} 1,2,3,4-tetrahydroacridin-9-amine (51)

The synthesis of $\mathbf{5 1}$ was reported earlier [16]. It was obtained as an orange solid, $56 \%$ yield. ${ }^{1} \mathrm{H}$ NMR $\left(300 \mathrm{MHz}, \mathrm{CDCl}_{3}\right) \delta 1.68(\mathrm{~m}, 2 \mathrm{H}), 1.88$ $(\mathrm{m}, 4 \mathrm{H}), 2.00(\mathrm{~d}, J=12.4,2 \mathrm{H}), 2.12(\mathrm{t}, J=11.4,2 \mathrm{H}), 2.67(\mathrm{~m}, 2 \mathrm{H}), 2.89$ $(\mathrm{d}, J=11.8,2 \mathrm{H}), 3.07(\mathrm{~m}, 2 \mathrm{H}), 3.54(\mathrm{~s}, 2 \mathrm{H}), 3.64(\mathrm{~m}, 1 \mathrm{H}), 7.28(\mathrm{~d}, J=2.3$, $1 \mathrm{H}), 7.31(\mathrm{~m}, 5 \mathrm{H}), 7.83(\mathrm{~d}, J=9.0,1 \mathrm{H}), 7.97(\mathrm{~d}, J=1.8,1 \mathrm{H}) .{ }^{13} \mathrm{C} \mathrm{NMR}$ (75MHz, $\mathrm{CDCl} 3) \delta 22.4,22.7,24.7,33.7,34.0,52.2,55.6,62.8,117.8$, 119.2, 124.1, 124.8, 127.0, 127.1, 128.1, 129.0, 134.1, 137.8, 147.3, 149.9, 159.4. MS (APCI) $m / z[\mathrm{M}+\mathrm{H}]^{+}$407.6. HPLC: Mobile phase A: water $10 \%+$ methanol $90 \%+$ formic acid $0.01 \%$ : Retention Time $=3.36 \mathrm{~min}$; Area under major peak: $96.9 \%$;Mobile phase B: water $10 \%$ + acetonitrile $90 \%$ + formic acid 0.01\%:Retention Time $=3.35$ min Area under major peak: $96.5 \%$. Separations were carried out on an ODS1, $4.6 \times 250$ $\mathrm{mm}, 10 \mu \mathrm{m}, 80 \AA$ (Waters Spherisorb $^{\circ}$ ) column. 51 was dissolved in methanol and injected through a $50 \mu$ loop at a flow rate of $1 \mathrm{ml} / \mathrm{min}$, with UV detection $(254 \mathrm{~nm})$.

\section{Determination of inhibitory effects on AChE and BChE}

Human acetycholinesterase (EC3.1.1.7, AChE), equine butyrylcholinesterase (EC3.1.1.8, BChE), dithiobis nitrobenzoic acid (DTNB), and substrates acetylthiocholine iodide and butyrylthiocholine iodide were purchased from Sigma Aldrich Chemical Co, Singapore. Cholinesterase activity was determined by the Ellman method [17]. The assay was carried out on a 96-well plate, with each well containing $300 \mu \mathrm{l}$ of $0.1 \mathrm{M}$ phosphate buffer (pH8.0), $10 \mu \mathrm{l}$ of $0.01 \mathrm{M} \mathrm{DTNB}, 1 \mu \mathrm{l}$ of 2 units / $\mathrm{ml}$ of AChE or BChE solution, $10 \mu \mathrm{l}$ of stock solution of test compound (prepared in DMSO) and $2 \mu \mathrm{l}$ of $0.075 \mathrm{M}$ substrate. The substrate was added last to start the reaction. Control wells containing the same composition but without test compound ( $10 \mu \mathrm{DMSO})$ were included to give the basal (uninhibited) AChE or BChE activity. Absorbance at $412 \mathrm{~nm}$ was recorded every minute for 10 minutes at $37^{\circ} \mathrm{C}$ on a BioRad Benchmark Plus microplate reader. The rate of reaction was taken as the slope of the absorbance curve over time. To account for nonenzymatic hydrolysis of the substrate, wells of the same composition as the above but without enzyme were concurrently monitored. Nonenzymatic hydrolysis was however not observed. The percent inhibition was calculated as the percentage of the reaction rate of test compound over that of vehicle control. Compounds were evaluated over a range of

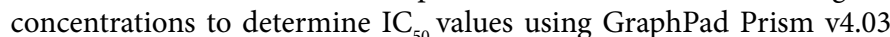
(GraphPad Software Inc., CA, US).

For the determination of inhibition type and $\mathrm{K}_{\mathrm{i}}$ (inhibitor constant), double reciprocal plots $(1 / \mathrm{v}$ versus $1 /[\mathrm{S}]$ where $\mathrm{v}=$ reaction rate and $S=$ substrate concentration) were constructed. A fixed amount of the enzyme $(1 \mu \mathrm{l}$ of 2 units / $\mathrm{ml}$ of $\mathrm{AChE}$ or BChE solution) was used for these determinations with substrate concentrations ranging from 0 to $450 \mathrm{mM}$ for both $\mathrm{AChE}$ and $\mathrm{BChE}$ assays. Determinations were made in the absence and presence of test compound. At least 3 different concentrations of test compound were used in each instance and the experiment was repeated on 3 different occasions.Data analysis was carried out with SigmaPlot v11.0 and Enzyme Kinetic v1.3 add-on (Systat Software, Inc, CA, US).

\section{Molecular Docking}

Docking of compound 51 was carried out on human AChE and equine BChE. The AChE-51 complex was prepared by aligning the X-ray crystal structure of the recombinant human AChE (rhAChE) apoenzyme derived from PDB 4EY7 [18] and Torpedo californica AChE (tAChE) co-crystalized with $\mathrm{N}^{1}, \mathrm{~N}^{5}$-bis $(1,2,3,4$-tetrahydroacridin9-yl) pentane-1,5-diamine (PDB code 2CMF) [19]. Once aligned, the bis-acridine ligand was modified to give 51, protonated at the tetrahydroacridine nitrogen ( $\mathrm{pKa} 9.8$ ) and energy minimized. Tyr337 (Phe 330 in tAChE) has been reported to be a "swinging gate" as it was able to change its position to accommodate different docked ligands [15]. For this reason, we assigned a "flexible mode" to Tyr 337 in our docking investigations to minimize steric clash. One $\mathrm{H}$-bond constraint was set to the protonated tetrahydroacridine ring $\mathrm{N}$ of 51 and the carbonyl oxygen of residue His447 in AChE.

The BChE homology model was developed based on the cocrystalized structure of rhAChE in complex with donepezil (PDB code $4 \mathrm{EY7}$ ) [18] and the primary sequence of horse BChE retrieved from Universal Protein Resource (entry code Q9N1N9) [19,20]. Alignment was carried out on MOE-Align in Molecular Operating Environment (MOE, 2009, Version 10, Chemical Computing Group Inc., Montreal, 
Quebec, Canada). The homology model was constructed on Homology Model (MOE) and the stereochemistry of the model was evaluated by the Protein Geometry application in MOE. Docking was carried out on GOLD v 5.2 (Cambridge Crystallographic Data Centre Software Ltd, Cambridge, UK). All amino acid residues within a $6 \AA$ radius of 51 were specified. One $\mathrm{H}$-bond constraint was set to the protonated tetrahydroacridine ring $\mathrm{N}$ of 51 and the carbonyl oxygen of residue His438 in BChE. As mentioned earlier, residue Tyr337 of AChE was set to a freely mobile mode but this was not done in $\mathrm{BChE}$ because the equivalent residue in BChE is the sterically smaller Ala 328 and no steric conflict was observed with it. Other parameters were set at default. As for the docking of donepezil, rhAChE-donepezil crystal structure was aligned with the BChE homology model and the donepezil was extracted into $\mathrm{BChE}$ as an initial complex. All amino acid residues within a $6 \AA$ radius of donepezil were selected as residues within the active site pocket. Genetic Algorithm (GA) was applied to identify potentially active binding conformations for ligand. Gold Score function was used as the fitness function.

\section{Determination of calculated physicochemical parameters}

Polar surface areas were (PSA, $\AA^{2}$ ) were estimated with the software ACD /Labs, Version 12.5, 2010, Advanced Chemistry Development, Ontario, CN. Clog P values were obtained from Chem Draw Ultra, Version 12.0.2.1075, Cambridge Soft.

\section{Results and Discussion}

The structures of the compounds investigated in this report are presented in Table 1 . The syntheses of these compounds were previously reported and evaluated by the authors in relation to antiprion and neuroprotective properties $[16,21,22]$. The compounds were classified into 7 groups depending on the nature of the scaffold and where relevant, the $\mathrm{N}$-substituted aromatic amino functionality on the scaffold. The 6-chloro-2-methoxyacridine-9-amine ring was present in Groups 1-4. The substituents attached to the 9-amino substituent were dialkylaminoalkyl (Group 1), substituted phenyl (Group 2), 1'-substituted phenylpiperidin-4-yl (Group 3) and miscellaneous groups (Group 4). The ring system in Group 5 was acridine-9-amine whereas in Groups 6 and 7, the core scaffolds were 6-chloro-1,2,3,4tetrahydroacridin-9-amine and 7-chloroquinolin-4-amine respectively. Miscellaneous side chains were attached to the aromatic amino functionality of these groups.

Active compounds were identified as those that inhibited AChE or BChE by more than $75 \%$. This limit was arbitrarily adopted because tacrine $(3 \mu \mathrm{M})$ was found to inhibit AChE and BChE by $91.3 \%(. \pm 0.5)$ and $98.3 \%( \pm 2.1)$ respectively. By this criteria, only two groups yielded compounds that potently inhibited AChE. They were Group 6 where all members (49-54) satisfied the stated criteria and Group 3 where only 3 compounds (39-41) were compliant. These compounds were generally more potent inhibitors of AChE except for a few members in Group $6(50,51)$ which were equally inhibitory on BChE. We noted that 9-aminoacridine (47, Group 5) was exceptionally potent against both AChE and BChE. In contrast, no compound in Groups 1,2, 4 and 7 was represented among the "actives" for AChE inhibition, although several members inhibited BChE by more than $75 \%$. These compounds were found in Group $1(1,4)$ and Group $2(6,10,24)$. Next, we proceeded to further characterized the inhibitory potencies of these shortlisted compounds by determining their $\mathrm{IC}_{50}$ values (Table 2).

With $\mathrm{IC}_{50}$ values on hand, a more definitive structure-activity relationship could now be deduced. First, introducing a 6-chloro atom to tacrine gave 49 , which was an exceptionally potent inhibitor of $\mathrm{AChE}$ $\left(\mathrm{IC}_{50} 8.8 \mathrm{nM}\right) .49$ inhibited AChE $\left(\mathrm{IC}_{50} 8.8 \mathrm{nM}\right)$ and $\mathrm{BChE}\left(\mathrm{IC}_{50} 15.2\right.$
$\mathrm{nM}$ ) to approximately the same extent, unlike tacrine which was a more selective BChE inhibitor ( $\left.\mathrm{IC}_{50 \mathrm{BChE}} 6.7 \mathrm{nM}, \mathrm{IC}_{50 \mathrm{AChE}} 184 \mathrm{nM}\right)$. Molecular docking by others [23] and ourselves showed that the 6-chloro atom of 49 occupied a pocket that was suitably lined with hydrophobic residues (Met443, Trp439, Pro446) in the human AChE binding site (PDB4EY7) [18]. These additional nonpolar interactions of 49 could conceivably enhance binding affinity, hence resulting in the large gain in inhibitory potency.

Functionalization of the 9-amino group of 49 gave Group 6, of which only 51 was comparable to 49 in terms of AChE inhibitory activity $\left(\mathrm{IC}_{50} 5.7 \mathrm{nM}\right.$ ). The side chain attached to the 9-amino group of 51 was 4'-benzyl-piperidin-1'-yl which is the side chain found in donepezil. Thus, 51 is a tacrine-donepezil hybrid and it is tempting to propose that the donepezil-like side chain contributed to its outstanding AChE inhibitory activity. Other side chains in Group 6 such as phenyl (52), substituted phenyl $(53,54)$ or 3-N'N'-diethylaminoethyl $(50)$ were weaker inhibitors than 51 . The Group 6 compounds were also weaker BChE inhibitors than 49 , with nanomolar BChE IC $_{50}$ limited to 50 and 51 only.

When the tetrahydroacridine ring of tacrine was replaced by acridine, the resulting compound 47 (9-aminoacridine) maintained the same inhibitory profile as tacrine, both in terms of $\mathrm{IC}_{50}$ values and preferred inhibition of BChE. Interestingly, substitution of the 9-amino of 47 with a 4-(diethylaminophenyl) group (48) sharply decreased both AChE and BChE inhibitory activities. The Group 2 compounds $(6,10,24)$ were similar to 48 in this regard: they were poor AChE inhibitors $\left(\mathrm{IC}_{50}>3 \mu \mathrm{M}\right)$ and modest $\mathrm{BChE}$ inhibitors $\left(\mathrm{IC}_{50} 0.6-1.6 \mu \mathrm{M}\right)$. We proposed that the poor AChE inhibitory activities of the Group 2 compounds owed more to the presence of the 9-(N-substituted phenyl) amino side chain (as seen from a comparison of 47 and 48) and less to the inclusion of 6-chloro and 2-methoxy groups to the acridine ring. Indeed, when the substituted phenyl ring was removed and replaced by the donepezil-like side chains present in 39-41, there was a marked improvement of AChE inhibitory activity as well as a return to selective inhibition of $\mathrm{AChE}$, comparable to that observed with several tetrahydroacridine analogs of Group 6. In contrast, replacing the substituted phenyl ring of Group 2 with a diethylaminoalkyl side chain (1, 4 of Group 1) greatly diminished AChE inhibitory activity while retaining modest $\mathrm{BChE}$ inhibitory activity.

Table 2 also lists the selectivity ratios ( $\mathrm{IC}_{50} \mathrm{AChE} / \mathrm{IC}_{50} \mathrm{BChE}$ ) of those test compounds $(47,49,50,51$, tacrine, donepezil) that had experimentally determined $\mathrm{IC}_{50}$ values. The selectivity ratios were broadly classified as follows. The first category consisted of compounds that preferentially inhibited AChE by at least 100 fold $($ ratios $<0.1)$. Donepezil and 51 were found in this category. The $2^{\text {nd }}$ class of compounds were those that inhibited AChE and BChE to almost the same extent, but with a small (2-fold) preference for AChE (ratios $\approx 0.5$ ). Compounds 49 and 50 were found in this category. The $3^{\text {rd }}$ category comprised compounds that preferentially inhibited $\mathrm{BChE}$ vis-à-vis $\mathrm{AChE}$ by at least 20 fold (ratio $>20$ ). Tacrine and 47 belonged to this category. It is tempting to propose that the highly selective AChE candidates (donepezil, 51) owed their strong AChE preference to the shared presence of the N-benzyl piperidinyl side chain in their structures. It is also significant to note that 51 bore the 6-chlorotetrahydroacridine scaffold which was also represented in 49 and 50 ( $2^{\text {nd }}$ category, near equal inhibition of AChE and BChE). The implication would be that the N-benzylpiperidine side chain of 51 played a critical role in enhancing binding affinity for AChE, more so that its 6-chlorotetrahydroacridine scaffold. As for the preferential BChE inhibition by tacrine and 47 , a comparison with the $2^{\text {nd }}$ category compounds $(49,50)$ would implicate the absence of the 6-chloro 
Citation: Jin H, Nguyen T, Mei-Lin G (2014) Acetylcholinesterase and Butyrylcholinesterase Inhibitory Properties of Functionalized Tetrahydroacridines and Related Analogs. Med chem 4: 688-696. doi:10.4172/2161-0444.1000213

\begin{tabular}{|c|c|c|c|c|}
\hline Compound & Structures & $\mathrm{AChE} \mathrm{IC}_{50}(\mathrm{nM})^{\mathrm{a}}$ & $\mathrm{BChE} \mathrm{IC}_{50}(\mathrm{nM})^{\mathrm{a}}$ & Selectivity Index $\left(\mathrm{IC}_{50} \mathrm{AChE} / \mathrm{IC}_{50} \mathrm{BChE}\right)^{\mathrm{b}}$ \\
\hline $\begin{array}{c}\text { Group } 1 \\
1\end{array}$ & & $>3000$ & $1149(977.6,1349)$ & Not applicable \\
\hline $\begin{array}{c}\text { Group } 1 \\
4\end{array}$ & & Not done & $947(735.8,1219)$ & Not applicable \\
\hline $\begin{array}{c}\text { Group } 2 \\
6\end{array}$ & & $>3000$ & $936.0(824.2,1063)$ & Not applicable \\
\hline $\begin{array}{c}\text { Group } 2 \\
10\end{array}$ & & $>3000$ & $660.7(495.5,881)$ & Not applicable \\
\hline $\begin{array}{c}\text { Group } 2 \\
24\end{array}$ & & $\mathrm{ND}^{\mathrm{e}}$ & $1634(1483,1801)$ & Not applicable \\
\hline $\begin{array}{c}\text { Group } 3 \\
39\end{array}$ & & $597.5(469.7,760.1)$ & $>3000$ & Not applicable \\
\hline $\begin{array}{c}\text { Group } 3 \\
40\end{array}$ & & $1077(911.3,1272)$ & $>3000$ & Not applicable \\
\hline $\begin{array}{c}\text { Group } 3 \\
41\end{array}$ & & $292.2(253.3,337.1)$ & $>3000$ & Not applicable \\
\hline $\begin{array}{c}\text { Group } 5 \\
47\end{array}$ & & $224.1(191.0,263.0)$ & $8.6(6.6,11.1)$ & 26 \\
\hline
\end{tabular}


Citation: Jin H, Nguyen T, Mei-Lin G (2014) Acetylcholinesterase and Butyrylcholinesterase Inhibitory Properties of Functionalized Tetrahydroacridines and Related Analogs. Med chem 4: 688-696. doi:10.4172/2161-0444.1000213

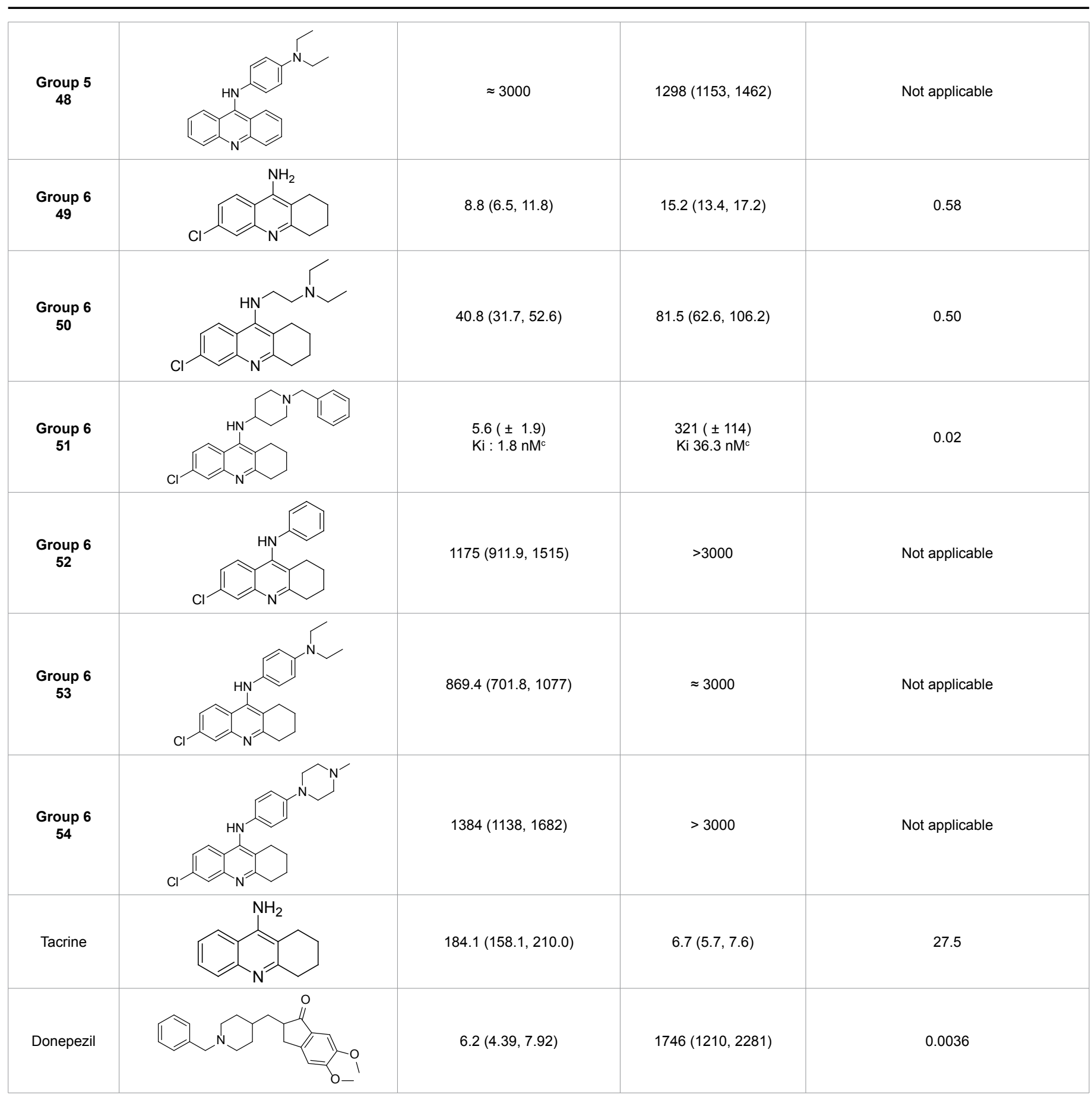

${ }^{\text {a }} C_{50}$ values were determined by GraphPad Prism v4.03 from at least three independent experiments. 95\% Confidence intervals are given in brackets. ${ }^{b}$ Ratios were obtained only for those compounds with experimentally determined IC50 values. Compounds which had estimated IC50 values were not considered.

Table 2: AChE and BChE inhibitory $I C_{50}$ values of selected compounds in Groups 1,2, 5 and 6.

substituent in tacrine and 47 for their pronounced BChE inhibitory preference. It is notable that 49 and 50 which were chloro substituted tetrahydroacridines failed to discriminate significantly between the two enzymes. Based on this limited number of compounds, our assessment was that the N-benzylpiperidine side chain favoured $\mathrm{AChE}$ selectivity (as seen in Category 1 compounds) while an unsubstituted scaffold favoured BChE inhibition (Category 3 compounds) .Category 2 compounds $(49,50)$ which lacked the N-benzylpiperidine side chain and had chloro substituted scaffolds, demonstrated nearly equal affinities for both enzymes.
The most potent AChE inhibitor identified in this investigation was the tacrine-donepezil hybrid 51 from Group $6\left(\mathrm{IC}_{50} 5.7 \mathrm{nM}\right)$. In terms of $\mathrm{AChE}$ inhibition, 51 was more potent than tacrine $\left(\mathrm{IC}_{50} 184\right.$ $\mathrm{nM}$ ) but it was comparable to donepezil ( $\mathrm{IC}_{50} 6.2 \mathrm{nM}$ ). In terms of BChE inhibition, $51\left(\mathrm{IC}_{50} 321 \mathrm{nM}\right)$ was weaker than tacrine $\left(\mathrm{IC}_{50} 6.7\right.$ $\mathrm{nM}$ ) but more potent than donepezil ( $\left.\mathrm{IC}_{50} 1746 \mathrm{nM}\right)$. No compound was identified to be a more potent BChE inhibitor than tacrine, although 47 (9-aminoacridine) and 49 (9-amino-6-chloro-1,2,3,4tetrahydroacridine) came close. They were however less interesting compounds because of their under-functionalized states. Mention 
should be made of the Group 6 analog 50: it was the next most potent BChE inhibitor $\left(\mathrm{IC}_{50} 82 \mathrm{nM}\right.$ ) after 49 besides being a stronger $\mathrm{AChE}$ inhibitor $\left(\mathrm{IC}_{50} 41 \mathrm{nM}\right)$ than tacrine.

We noted that tacrine-donepezil hybrids were generally large molecules with physicochemical features that do not promote permeation across the blood brain barrier (BBB) which is an important prerequisite for activity in $\mathrm{AD}$. Some examples of such hybrids (61-63) are provided in Figure 2. The number of H-bond donors and acceptors, polar surface area, molecular weight and lipophilicity are critical molecular properties that affect BBB permeability [24]. Threshold values have been cited for these properties such as polar surface area not exceeding 60-70 $\AA^{2}$, molecular weight less than 450 , number of $\mathrm{N}$ and $\mathrm{O}$ atoms kept at not more than 6 and ClogP greater than the sum of $(\mathrm{N}+\mathrm{O})$ atoms $[25,26]$. As seen from Figure 2, many of these properties were breached in the tacrine-donepezil hybrids 61-63. For example, PSA values of 62 and 63 exceeded the cut-off values of 60 $70 \AA^{2}$, and the ClogP of 61 was only marginally greater than the sum of $\mathrm{N}$ and $\mathrm{O}$ atoms. In contrast, the molecular weight (405), number of $\mathrm{N}$ and $\mathrm{O}$ atoms (3) and polar surface area $\left(28.2 \AA^{2}\right)$ of 51 complied with criteria required for permeation across the blood brain barrier. Thus 51 effectively combined nanomolar cholinesterase inhibitory properties with a pharmaceutically "friendly" profile that favoured BBB permeability.
Next, we examined the kinetics of AChE inhibition by 51 . As shown in Figure 3A, 51 was found to be a non-competitive (mixed type) of AChE, implying that it binds to both the enzyme and the enzymesubstrate complex (ES) [27]. Furthermore, the double reciprocal plot displayed a nest of lines that converged above the $\mathrm{x}$-axis, indicating that 51 had a stronger affinity for the free enzyme than the ES complex [27-30].Ki for AChE inhibition by 51 was $1.8 \mathrm{nM}$. On the other hand, 51 inhibited BChE with competitive kinetics (Figure 3B). Ki for BChE inhibition was found to be $36.3 \mathrm{nM}$.

We then proceeded to examine the binding mode of 51 in the human $\mathrm{AChE}$ and equine $\mathrm{BChE}$ binding pockets. The docking results showed that the tetrahydroacridine ring of 51 was accommodated at the bottom of the rhAChE active site gorge, sandwiched between the indole ring of Trp86 and the phenyl ring of Tyr337 (Figure 4A). The protonated tetrahydroacridine ring $\mathrm{N}$ was $\mathrm{H}$ bonded $(2.99 \AA)$ to the backbone carbonyl O of His 438 which is part of the catalytic triad in the CAS. The piperidine ring of 51 was positioned in the mid-gorge region, with $\mathrm{H}$ bonding between the protonated piperidine $\mathrm{N}$ and the phenolic $\mathrm{OH}$ of Tyr124. At the opening of the gorge which is part of the PAS, the N-benzyl side chain of 51 displaced classic $\pi \pi$ stacking with Trp286.

We compared the orientation of 51 with that of tacrine and donepezil in the AChE binding pocket. The co-crystalized structure

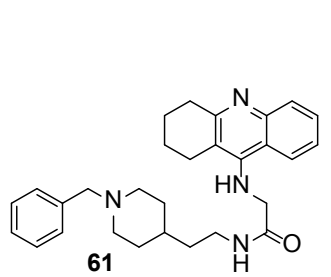

$\begin{array}{ll}\text { MW } 457 & I_{50 A C h E} 6 \mathrm{nM} \\ \text { PSA } 57.3 & \mathrm{IC}_{50 \text { BChE }} 75 \mathrm{nM} \\ \text { ClogP } 5.96 & \\ \mathrm{~N}+\mathrm{O}=5 & \end{array}$

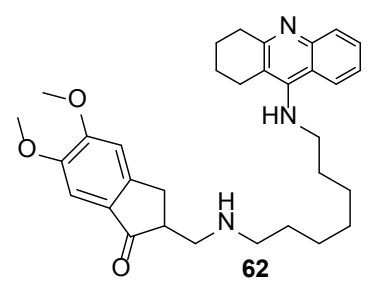

MW $516 \quad I_{50 A C h E} 25 \mathrm{nM}$

PSA $72.5 \quad I_{50 \text { BChE }} 0.6 \mathrm{nM}$

ClogP 7.16

$\mathrm{N}+\mathrm{O}=5$
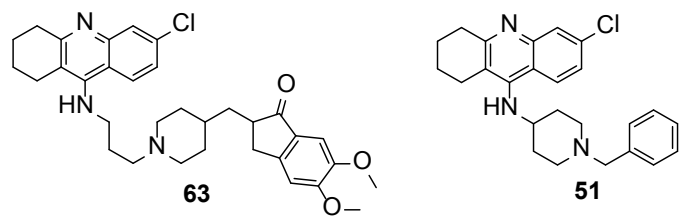
MW 562
IC 50AChE $0.27 \mathrm{nM}$
PSA 63.7
ClogP 7.86
$I_{50 \text { BChE }} 66.3 \mathrm{nM}$

$\mathrm{N}+\mathrm{O}=7$

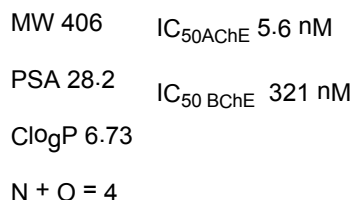

$\mathrm{N}+\mathrm{O}=4$

Figure 2: Structures of reported tacrine-donepezil hybrids with AChE inhibitory activity. Molecular weights (MW) and polar surface areas (PSA, $\left.\AA^{2}\right)$ were estimated (ACD /Labs, Version 12.5, 2010). Clog P values were obtained from ChemDraw, Version 12, Cambridgesoft. IC for $_{50}$ fChE were from human $(63,51)[24]$,rat $(61)[25]$ and bovine $(62)[26]$ sources. $I C_{50}$ for BChE were obtained from human $(62,63)[26,24]$, rat $(61)$ [ 25] and equine $(51)$ sources.
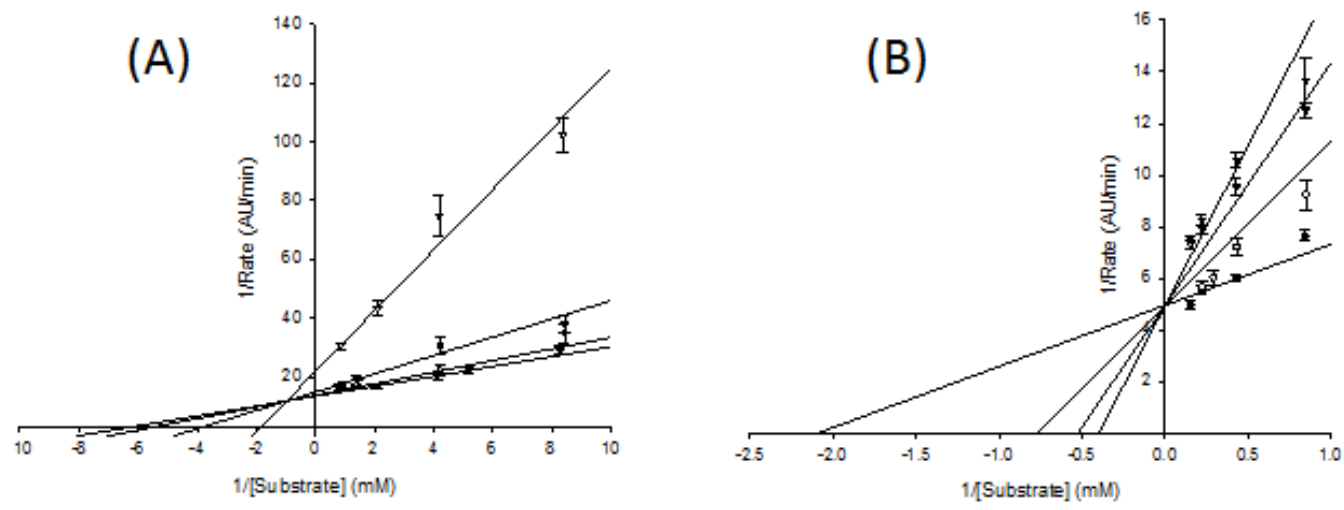

Figure 3: Overlaid double reciprocal plots of initial enzyme velocity at increasing substrate (acetylthiocholine concentrations) in the absence ( $\bullet$ ) and presence of 51. (A) AChE as enzyme. $\mathrm{K}_{\mathrm{m}}$ of AChE was $0.15 \mathrm{mM} .51$ was tested at o $(0.3 \mathrm{nM}), \boldsymbol{\nabla}(1.6 \mathrm{nM})$ and $\nabla(9.5 \mathrm{nM})$. (B) BChE as enzyme. $\mathrm{K}_{\mathrm{m}}$ of BChE was $0.54 \mathrm{mM} .51 \mathrm{was}$ tested at o $(62 \mathrm{nM}), \nabla(108 \mathrm{nM})$ and $\nabla(153 \mathrm{nM})$. 
of tacrine and AChE (electric eel, Torpedo californica) was used as reference [12]. The amino acid sequences in the active sites of the eel and human AChE were reported to be highly conserved [31] which justified our comparison of the binding modes of 51 and tacrine in AChE from different species. As seen from Figure 4B, there was excellent alignment of the tetrahydroacridine rings of 51 and tacrine at the base of the binding pocket.Both rings were involved in $\pi \pi$ stacking interactions with Trp86 (Trp 84 in eel AChE) and Tyr337 (Phe330 in eel AChE). $\mathrm{H}$ bonding of the tetrahydroacridine nitrogen (protonated) with the backbone carbonyl of His447 (His 440 in eel AChE) was evident. Unlike tacrine, 51 have a 6-chloro substituent on the tetrahydroacridine ring and it was found to be favourably positioned in a pocket that was flanked by hydrophobic residues Met443, Trp439 and Pro446. Docking of the acridine 47 and tetrahydroacridine 49 in the AChE (eel) binding pocket also showed that both rings were aligned in a similar way as tacrine.

A comparison of the binding poses of 51 and donepezil in the human AChE binding site (PDB4EY7) [21] was next examined (Figure $4 \mathrm{C}$ ). Interestingly, it was the benzyl side chain of donepezil, rather than its indanone ring that was aligned to the tetrahydrohydroacridine ring of 51 at the base of the gorge. The methoxy substituted indanone ring of donepezil was positioned at the opening of the binding pocket by $\pi$ stacking (Trp 286) and $\mathrm{H}$ bonding (indanone carbonyl oxygen and backbone $\mathrm{NH}$ of Phe295). We noted that the piperidine ring of donepezil was inserted deeper into the binding pocket that its counterpart in 51. Consequently, the piperidine nitrogen of 51 was electrostatically attracted to the carboxylate of Asp74 whereas no such attraction was accessible to the piperidine nitrogen of donepezil. Although we had earlier proposed that strong AChE inhibition was associated with the N-benzylpiperidine side chain of donepezil and 51, docking has cast fresh insight into their inhibitory potencies and it would seem that both the side chain and the aromatic scaffold (indanone and tetrahydroacridine in donepezil and 51 respectively) were contributory. Notably, the indanone ring of donepezil had more productive interactions with the PAS residues at the opening of the gorge, whereas in the case of 51, more interactions were found at the base of the gorge (CAS).

Unlike the rich array of interactions between 51 and the rhAChE binding pocket, conspicuously fewer interactions were noted for 51 in the BChE pocket. When the active sites of the two enzymes were compared, we found that residues Tyr124, Trp286 and Tyr337 which were involved in key interactions between 51 and AChE, had been replaced by Gln119, Val288 and Ala328 in BChE. Hence, when the docking pose of 51 in $\mathrm{BChE}$ was examined, only the tetrahydroacridine ring of 51, and not its N-benzylpiperidine side chain, was involved in interactions with the binding pocket (Figure $5 \mathrm{~A}$ ). There was $\pi \pi$ interactions between the tetrahydroacridine ring and Trp82 at the base of the gorge and $\mathrm{H}$ bonding between the protonated $\mathrm{N}$ of the ring and the backbone carbonyl $\mathrm{O}$ of His438. Clearly, the replacement of Tyr337, Tyr124 and Trp286 with the smaller non-aromatic residues in BChE abrogated interactions involving these residues, resulting in the significantly weaker binding affinity of 51 for BChE. Notwithstanding, 51 was still a more potent inhibitor of BChE than donepezil. To have a better understanding why this is so, we examined the docking poses

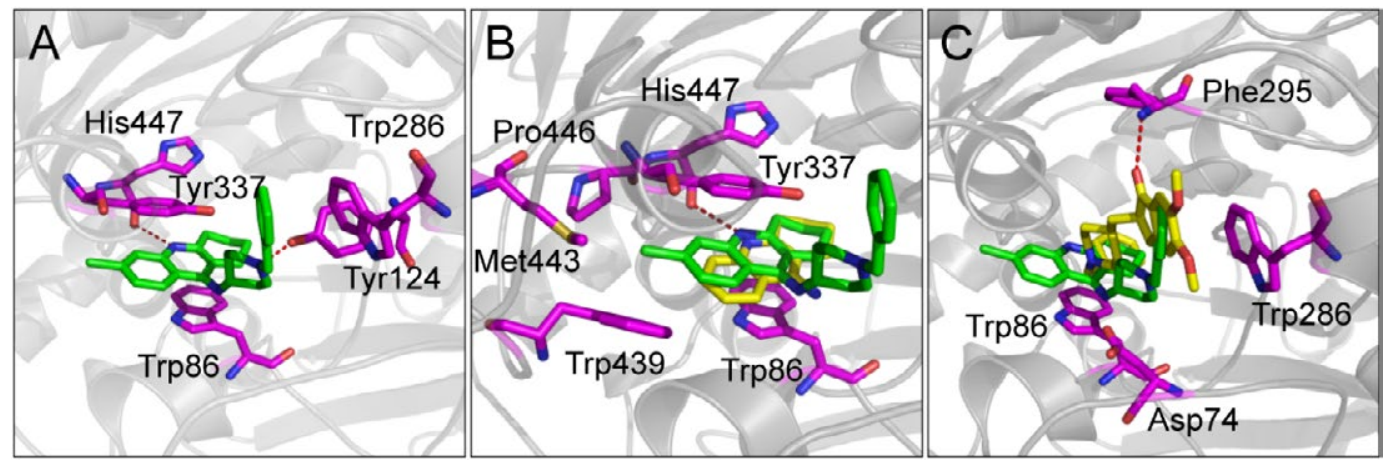

Figure 4: (A) Docking pose of 51 in the $A C h E$ binding pocket. $\mathrm{N}$ and $\mathrm{O}$ atomsare shown in blue and red respectively, $\mathrm{C}$ atoms of residue and $\mathbf{5 1}$ are in magenta and green respectively. (B) Binding poses of $\mathbf{5 1}$ and tacrine in AChE binding pocket (PDB1ACJ) [9]. (C) Binding poses of 51 and donepezil in AChE binding pocket (PDB4EY7) [15]. Tacrine and donepezil are depicted in yellow.

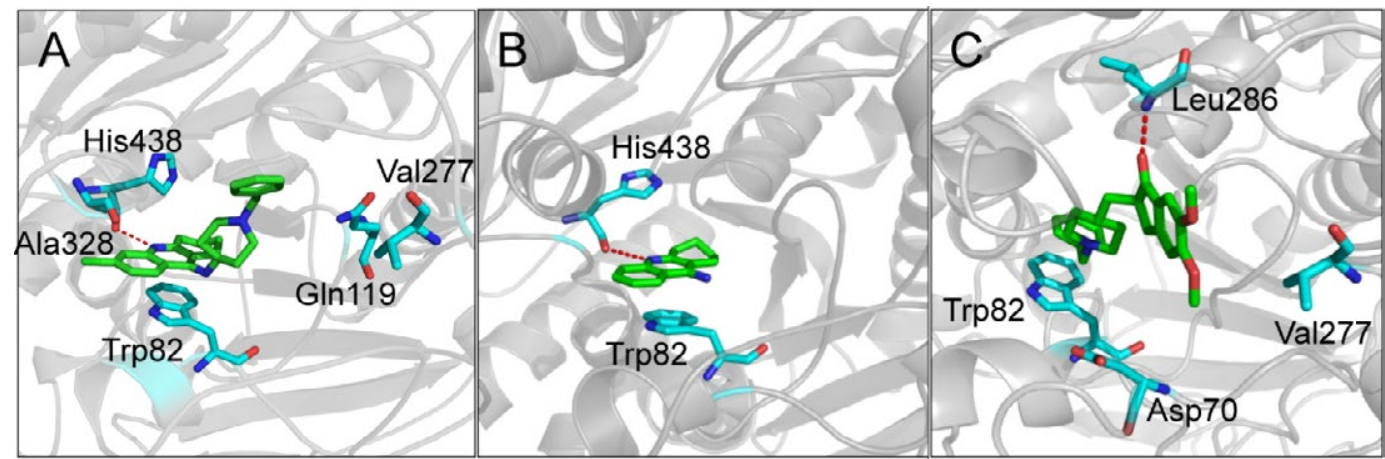

Figure 5: (A) Docking pose of 51 in the BChE homology model binding pocket. $\mathrm{N}$ and $\mathrm{O}$ atoms are shown in blue and red respectively, $\mathrm{C}$ atoms of residue and $\mathbf{5 1}$ are in cyan and green respectively. (B) Binding pose of tacrine in human BChE binding pocket (PDB 4BDS) [29]. (C) Binding pose of donepezil in BChE homology binding pocket. 
of tacrine in human BChE (PDB 4BDS) [32] and donepezil in our BChE homology model. We found that the tetrahydroacridine ring of tacrine was stacked against Trp82, as in 51 (Figure 5B). Compounds 47 and 49 assumed similar poses as tacrine in human BChE. On the other hand, donepezil established few significant interactions at the BChE binding pocket (Figure 5C) which could have accounted for its weaker BChE inhibitory activity. Thus the tetrahydroacridine ring of 51 is a key contributor to its BChE inhibitory activity. There is evidence to show that $\mathrm{BChE}$ levels progressively increased in the $\mathrm{AD}$ afflicted brain [33], possibly to compensate for the steady decline in AChE levels and impaired cholinergic synapses which are characteristic of the disorder [2]. In this regard, a dual inhibitor of AchE and BchE would be preferred to one that inhibits only AChE or BChE.

\section{Conclusion}

In summary, we have identified the tacrine-donepezil hybrid 51 as a potent dual binding AChE inhibitor with physicochemical properties that fall within the threshold limits for BBB permeability. In spite of its smaller and more compact structure, molecular docking showed that 51 occupied both the CAS and PAS sites in AChE via the tetrahydroacridine ring and $\mathrm{N}$ (1-benzylpiperidin-4-yl) side chain respectively. The dual binding character of 51was further supported by its non-competitive inhibition of $\mathrm{AChE}$, which was also observed for other dual-binding inhibitors [20,23]. Hence, 51 is a more potent AChE inhibitor than tacrine (a single site binder) and comparable to donepezil, another dual binding inhibitor.

\section{Acknowledgements}

The work was supported by the National University of Singapore (NUS) Academic research Fund R148000064112 to GML and Scientific Research Fund of Ningbo University (XYL11014) and KC Wong Magna Fund in Ningbo University to Haixiao JIN.

\section{References}

1. Small GW (1992) Tacrine for treating Alzheimer's disease. JAMA 268: 25642565.

2. Bartus RT, Dean RL 3rd, Beer B, Lippa AS (1982) The cholinergic hypothesis of geriatric memory dysfunction. Science 217 : 408-414.

3. Dunnett SB, Fibiger HC (1993) Role of forebrain cholinergic systems in learning and memory: relevance to the cognitive deficits of aging and Alzheimer's dementia. Prog Brain Res 98: 413-420.

4. Watkins PB, Zimmerman HJ, Knapp MJ, Gracon SI, Lewis KW (1994) Hepatotoxic effects of tacrine administration in patients with Alzheimer's disease. JAMA 271: 992-998.

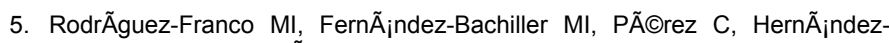
Ledesma B, BartolomÃ $\odot$ B (2006) Novel tacrine-melatonin hybrids as dualacting drugs for Alzheimer disease, with improved acetylcholinesterase inhibitory and antioxidant properties. J Med Chem 49: 459-462.

6. Thiratmatrakul S, Yenjai $C$, Waiwut $P$, Vajragupta $O$, Reubroycharoen $P$, et al. (2014) Synthesis, biological evaluation and molecular modeling study of novel tacrine-carbazole hybrids as potential multifunctional agents for the treatment of Alzheimer's disease. Eur J Med Chem 75: 21-30.

7. Perry G, Cash AD, Smith MA (2002) Alzheimer Disease and Oxidative Stress. J Biomed Biotechnol 2: 120-123.

8. Bautista-Aguilera OM, Esteban G, Bolea I, Nikolic K, Agbaba D, et al. (2014) Design, synthesis, pharmacological evaluation, QSAR analysis, molecular modelling and ADMET of novel donepezil-indolyl hybrids as multipotent cholinesterase/monoamine oxidase inhibitors for the potential treatment. Eur J Med Chem 75: 82-95.

9. Rosini M, Simoni E, Bartolini M, Cavalli A, Ceccarini L, et al. (2008) Inhibition of acetylcholinesterase, beta-amyloid aggregation, and NMDA receptors in Alzheimer's disease: a promising direction for the multi-target-directed ligands gold rush. J Med Chem 5: 4381-4384.

10. Lange JH, Coolen HK, van der Neut MA, Borst AJ, Stork B, et al. (2010) Design, synthesis, biological properties, and molecular aliforni investigations of novel tacrine derivatives with a combination of acetylcholinesterase inhibition and cannabinoid CB1 receptor antagonism. J Med Chem 53: 1338-1346.

11. Sussman JL,Harel M, Frolow F, Oefner C, Goldman A, et al. (1991) Atomic structure of acetylcholinesterase from Torpedo californica: a prototypic acetylcholine-binding protein. Science 253: 872-879.

12. Harel M, Schalk I, Ehret-Sabatier L, Bouet F, Goeldner M, et al. (1993) Quaternary ligand binding to aromatic residues in the active-site gorge of acetylcholinesterase. Pro cNatl Acad Sci U S A 90: 9031-9035.

13. Pang YP, Kozikowski AP (1994) Prediction of the binding sites of huperzine A in acetylcholinesterase by docking studies. J Comput Aided Mol Des 8: 669-681.

14. Nightingale SL (1993) From the Food and Drug Administration. JAMA 270: 1672.

15. Kryger G, Silman I, Sussman JL (1999) Structure of acetylcholinesterase complexed with E2020 (Aricept): implications for the design of new antiAlzheimer drugs. Structure 7: 297-307.

16. Nguyen T, Sakasegawa Y, Doh-Ura K, Go ML (2011) Anti-prion activities and drug-like potential of functionalized quinacrine analogs with basic phenyl residues at the 9-amino position. Eur J Med Chem 46: 2917-2929.

17. Ellman GL, Courtney KD, Andres V Jr, Feather-stone RM (1961) A new and rapid colorimetric determination of acetylcholinesterase activity. Biochem Pharmacol 7: 88-95.

18. Cheung J, Rudolph MJ, Burshteyn F, Cassidy MS, Gary EN, et al. (2012) Structures of human acetylcholinesterase in complex with pharmacologically important ligands. J Med Chem 55: 10282-10286.

19. Rydberg EH, Brumshtein B, Greenblatt HM, Wong DM, Shaya D, et al. (2006) Complexes of alkylene-linked tacrine dimers with Torpedo californica acetylcholinesterase: binding of Bis5-tacrine produces a dramatic rearrangement in the active-site gorge. J Med Chem 49: 5491-5500.

20. Wierdl M, Morton CL, Danks MK, Potter PM (2000) Isolation and characterization of a cDNA encoding a horse liver butyrylcholinesterase: evidence for CPT-11 drug activation. Biochem Pharmacol 59: 773-781.

21. Nguyen TH, Lee CY, Teruya K, Ong WY, Doh-ura K, et al. (2008) Antiprion activity of functionalized 9-aminoacridines related to quinacrine. Bioorg Med Chem 16: 6737-6746.

22. Nguyen T, Yang T, Go ML (2014) Functionalized acridin-9-yl phenylamines protected neuronal HT22 cells from glutamate-induced cell death by reducing intracellular levels of free radical species. Bioorg Med Chem Lett 24: 1830-1838.

23. Camps $P$, Formosa $X$, Galdeano $C$, Muñoz-Torrero D, Ramírez L, et al. (2009) Pyrano[3,2-c]quinoline-6-chlorotacrine hybrids as a novel family of acetylcholinesterase- and beta-amyloid-directed anti-Alzheimer compounds. J Med Chem 52: 5365-5379.

24. Kerns EH, Di L (2008) Drug-like properties: Concepts, Structure Design and Methods. Academic Press, Amsterdam, 2008, Chapter 10.

25. Clark DE (2003) Insilico prediction of blood-brain barrier permeation. Drug Discov Today 8: 927-933.

26. Lobell M, Moln $\tilde{A}_{j}$ L, KeserÃGM (2003) Recent advances in the prediction of blood-brain partitioning from molecular structure. J Pharm Sci 92: 360-370.

27. Camps P, Formosa X, Galdeano C, Gómez T, Muñoz-Torrero D, et al. (2008) Novel donepezil-based inhibitors of acetyl- and butyrylcholinesterase and acetylcholinesterase-induced beta-amyloid aggregation. J Med Chem 5: 35883598.

28. Shao D, Zou C, Luo C, Tang X, Li Y (2004) Synthesis and evaluation of tacrine-E2020 hybrids as acetylcholinesterase inhibitors for the treatment of Alzheimer's disease. Bioorg Med Chem Lett 14: 4639-4642.

29. Alonso D, Dorronsoro I, Rubio L, Muñoz P, García-Palomero E, et al. (2005) Donepezil-tacrine hybrid related derivatives as new dual binding site inhibitors of AChE. Bioorg Med Chem 13: 6588-6597.

30. Copeland RA (2005) Evaluation of enzyme inhibitors in drug discovery. WileyInterscience: New Jersey, Chapter 3.

31. Kryger G, Sussman JL (1998) 3D structure of a complex of human recombinant acetylcholinesterase with fasciculin-II at $2.7 \mathrm{~A}$ resolution. Structure and function of cholinesterases and related proteins; Plenum: NY 323-326.

32. Nachon F, Carletti E, Ronco C, Trovaslet M, Nicolet Y, et al. (2013) Crysta structures of human cholinesterases in complex with huprine $\mathrm{W}$ and tacrine: elements of specificity for anti-Alzheimer's drugs targeting acetyl- and butyrylcholinesterase. Biochem J 453: 393-399.

33. Giacobini E (2004) Cholinesterase inhibitors: new roles and therapeutic alternatives. Pharmacol Res 50: 433-440. 